Burcu ERBAŞ

http://dx.doi.org/10.21278/brod70404

ISSN 0007-215X

eISSN 1845-5859

\title{
THE TURBULENT BOUNDARY LAYER AND FRICTIONAL DRAG CHARACTERISTICS OF NEW GENERATION MARINE FOULING CONTROL COATINGS
}

UDC 532.526:532.517.4:62-408.8

Original scientific paper

\begin{abstract}
Summary
The turbulent boundary layer over rough surfaces has been a widely studied research topic since most of the engineering wall-bounded turbulent flows develop under the influence of surface roughness. Accordingly, the research on rough wall turbulent boundary layer has gone a long way. However, unresolved major problems can still be found in this area such as the unsatisfying correlation of roughness and frictional drag for irregular engineering surfaces and the discrepancies about the validity of wall similarity. This study aims to contribute to further understanding of the rough-wall turbulent boundary layer flows developed over marine fouling control coatings along with the investigation of their friction drag properties. Two-dimensional Laser Doppler Velocimetry (LDV) experiments were conducted consisting of zero-pressuregradient turbulent boundary layer measurements over surfaces coated with marine fouling control coatings together with smooth and rough references in the Emerson Cavitation Tunnel of Newcastle University by using flat plate test models. Six different surfaces were included in the experimental campaign, which consist of one hydraulically smooth reference, a sand grit surface and four surfaces coated with fouling control coatings including Self-Polishing Copolymer (SPC) and Foul(ing) Release (FR) types, applied either by spraying or rollering. The mean velocity, local skin friction drag and roughness functions were calculated and discussed for the tested surfaces. In complementing the boundary layer tests, roughness measurements of the test surfaces were carried out by using a laser profilometry. Two new relations were proposed for the correlation of the roughness properties and roughness functions within the covered Reynolds number range. However; further work is needed in order to ensure the validity of the proposed relations at higher Reynolds number ranges.
\end{abstract}

Keywords: Marine fouling control coatings; turbulent boundary layer; roughness-friction drag correlation. 


\section{Introduction}

The surfaces of marine structures or vehicles that are subject to seawater are exposed to fouling coverage in time. Such unwanted biological accumulation on the surface increase the surface roughness and thus the frictional resistance of the surface by altering the turbulent boundary layer flow. It is known that, with the existence of hard-shell heavy fouling in the wetted surface, the ship resistance may increase by up to $86 \%$, which leads to remarkable added fuel consumption [1,2]. More than $100 \%$ increase was observed in the frictional resistance coefficient of a container ship for fouled condition in the recent study of [3]. The marine antifouling paints are used in order to prevent such fouling of the wetted surfaces of marine vehicles. The marine fouling control coatings with copper and co-biocides are under environmental scrutiny and totally environment friendly non-toxic coatings are favoured. As a consequence, the Foul-Release (FR) fouling control coatings, which are the most competitive alternatives to the biocidal ones, gradually supersede the Self-Polishing-Copolymers (SPC). On the other hand, in the literature, some anti-fouling marine coatings were reported to even lower the frictional resistance characteristics $[4,5]$. Moreover, the energy efficiency regulations of IMO for ships entered into force beginning from 2013, which include performance-based standards for ships in order to reduce the greenhouse gas emissions. Therefore, the frictional drag characteristics of the fouling control coatings in the newly applied and clean conditions gained even more importance along with their antifouling properties. Accordingly, there is a continually growing commercial interest and hence support for research and development activities for new coating systems with particular interest to their hydrodynamic characteristics.

The surfaces coated with marine fouling control coatings generally have small average amplitudes of surface roughness -although this highly depends on the application type and procedure- and turbulent rough wall boundary layers are supposed to form in the transitionally rough flow regime over them. Such surfaces are also good examples that show irregular and complex roughness structure. The research on rough wall turbulent boundary layer has gone a long way since the first surface roughness effect studies. However, there still exists unresolved major problems such as the unsatisfying correlation of roughness and frictional drag for irregular engineering surfaces such as marine fouling control coatings. Discrepancies about the validity of wall similarity are also observed. Besides, there is a lack of data on turbulent boundary layer flow over irregularly rough real engineering surfaces and the research in the literature accumulate on geometrically defined regular and mostly two-dimensional roughness types. Examples to regular rough wall turbulent boundary layer research include experimental studies for surfaces covered with spheres, bars, pyramids, meshes, sand particles and sand paper as roughness $[6,7,8,910,11,12,13,14]$. Although the studies about irregular rough wall boundary layer flow is rather limited, it continues to gain interest between some researchers such as $[4,5,15,16,17,18,19,20,21,22]$. It is noteworthy that most of the mentioned studies are about surfaces coated with marine fouling control coatings or fouling.

There is also a growing interest for simulation of rough wall boundary layers growing over marine fouling control coatings or fouling by using Computational Fluid Mechanics (CFD). [23] simulates the flat plate experiments of [17] for antifouling coated surfaces by adopting the roughness scale given in the experimental work to the wall functions in order to calculate the 
encountered frictional resistance difference by using CFD. Whilst, in [24] and [25] the effect of marine coatings, biofilm and barnacle fouling on frictional and wave resistance of a fullscale ship is predicted by using (Reynolds Averaged Navier Stokes (RANS) modelling. [26] presents CFD simulations in order to predict the effect of biofilm on the ship resistance by using the effective roughness length scale of [27] for biofilm along with developing a relevant roughness function to implement within wall functions.

On the other hand, looking for a correlation between the roughness parameters and the frictional drag is comparatively easier for regular rough surfaces, since the selection of the characteristic roughness parameter is obvious and the total number of roughness parameters are far limited for such geometrically defined roughness. The number of possible effective roughness parameters get larger and larger as the surface gets more complex. [28] includes the suggested frictional drag-roughness correlations in the literature which mostly accumulates on geometrically defined regular rough surfaces. [17] show an agreement with the ColebrookWhite law [29] for surfaces coated with marine fouling control coatings which were being used at that time with average roughness height as the effective roughness parameter. [30] and [4] used a similar parameter as well as a combination of average roughness height and mean absolute slope for such a correlation. However, the proposed combination did not provide a satisfactory fit, as the behavior of the roughness functions they found was quite different from the Colebrook-White correlation. A similar situation can be found in [5], in which nanostructured new fouling control coatings were tested as rough walls in turbulent boundary layer experiments. It was observed that both commercially available fouling control coatings and nanostructured ones exhibited much lower roughness functions than the Colebrook-White law in the tested Reynolds number range.

The lack of studies in the literature, on turbulent boundary layer flows over transitionally rough engineering surfaces underlies the need of new research for such flows. Accordingly, in this study, it is aimed to investigate the frictional resistance properties of turbulent boundary layers growing over surfaces coated with new generation marine fouling control coatings. Within this aim, flat plate turbulent boundary layer experiments were carried out under the influence of zero pressure gradient. Velocity measurements were performed with a two-dimensional DANTEC Laser Doppler Velocimetry (LDV) system. All experiments were conducted at the Emerson Cavitation Tunnel in the School of Marine Science and Technology, Newcastle University. A total of six different plates were tested, including surfaces coated with different types of marine fouling control coatings and two reference surfaces which are hydraulically smooth and completely rough. An SPC, a hard coating (HC), and a FR type antifouling were used among the tested marine fouling control coatings. The FR type antifouling was coated using both spray (FR) and roller (FRR); so that it was also possible to see the difference effects of the application methods. In addition to boundary layer tests, roughness measurements were made on all tested surfaces by using a laser profilometry and several roughness parameters were calculated and presented. As a result of the boundary layer experiments, mean velocity profiles, frictional resistances, roughness functions and correlations between roughness and frictional resistance were investigated. 
None of the tested marine fouling control coatings showed compliance with Colebrook-White law with their roughness functions creating a completely distinct trend in the range of $10 \leq k_{s}^{+}<100$ with much lower than expected roughness function values. Accordingly, two new correlations between roughness and frictional resistance have been proposed to represent the behavior of the new generation marine fouling control coated surfaces by using a complex roughness length scale [28].

\section{Experiments}

\section{$2.1 \quad$ Test Set-Up and Data Collection}

A rigid flat test plate of $3.924 \mathrm{~m}$ in length was used for the tests which allowed $600 \mathrm{~mm}$ long and $220 \mathrm{~mm}$ wide flat plate test specimens to be fitted on it. The test plate had a nose section with an aerofoil shaped leading edge that was deployed in order to slowly lead the incoming flow from the contraction part of the tunnel so that flow behind the test plate was eliminated. 36 grade sand paper of $400 \mathrm{~mm}$ length was used as a turbulence stimulator following the leading edge of the plate. The boundary layer measurements were performed at the midline of the test plates and at $500 \mathrm{~mm}$ distances from their leading edges. Accordingly, a distance of $2724 \mathrm{~mm}$ was achieved for the boundary layer growth. The details of the test plate described above can be seen in Fig. 1. Steel plates with a length of $600 \mathrm{~mm}$ and a height of $220 \mathrm{~mm}$ were coated with the selected marine fouling control coatings for the boundary layer testing. The hydraulically smooth surface (ACRYLIC) was specially cut out from an acrylic plate. The rough reference surface (SAND40), which is expected to be in the fully-rough flow regime, was obtained by coating a steel plate with 40 grade sandpaper. The summary of the tested surfaces is given in Table 1 along with their abbreviations. The test plates were mounted on the large flat plate as shown in Fig. 1, respectively, and the tests were carried out at a distance of 500 $\mathrm{mm}$ (POS1) from the beginning of the test plate. The experiments were carried out at three different free flow rates of 2, 4, and $6 \mathrm{~m} / \mathrm{s}$. Thus, the local Reynolds number at the test location varied between $5.45 \times 10^{6}$ and $1.63 \times 10^{7}$. The streamwise turbulence intensity of the incoming flow varied between $1.4 \%$ to $2 \%$ whilst the transverse turbulence intensity stayed around $2 \%$ for the covered flow rates.

In the boundary layer, velocity-time data, were collected by a DANTEC LDV system in two dimensions. A $60 \mathrm{~mm}$ LDV probe was used with a $5^{\circ}$ slope to collect data near the wall. In addition, the probe was rotated $45^{\circ}$ so that the velocity component in the wall-normal direction, which is much lower than the one in the direction of free flow, could be better identified. A 500 $\mathrm{mm}$ focal length lens was used along with a 1.98 beam expander to reduce the probe volume. Spherical glass spheres with a diameter of $2 \mu \mathrm{m}$ were used as seeding to reflect the laser beam.

Boundary layer velocity data were collected at 80 points in the boundary layer for 100 to 120 seconds at each point, so that at least 10000 data points were collected near the wall where the data rate was low, and about 50,000 data were collected as the distance from the wall rapidly increased. The data rate ranged from 100 to $1200 \mathrm{~Hz}$. 
2724

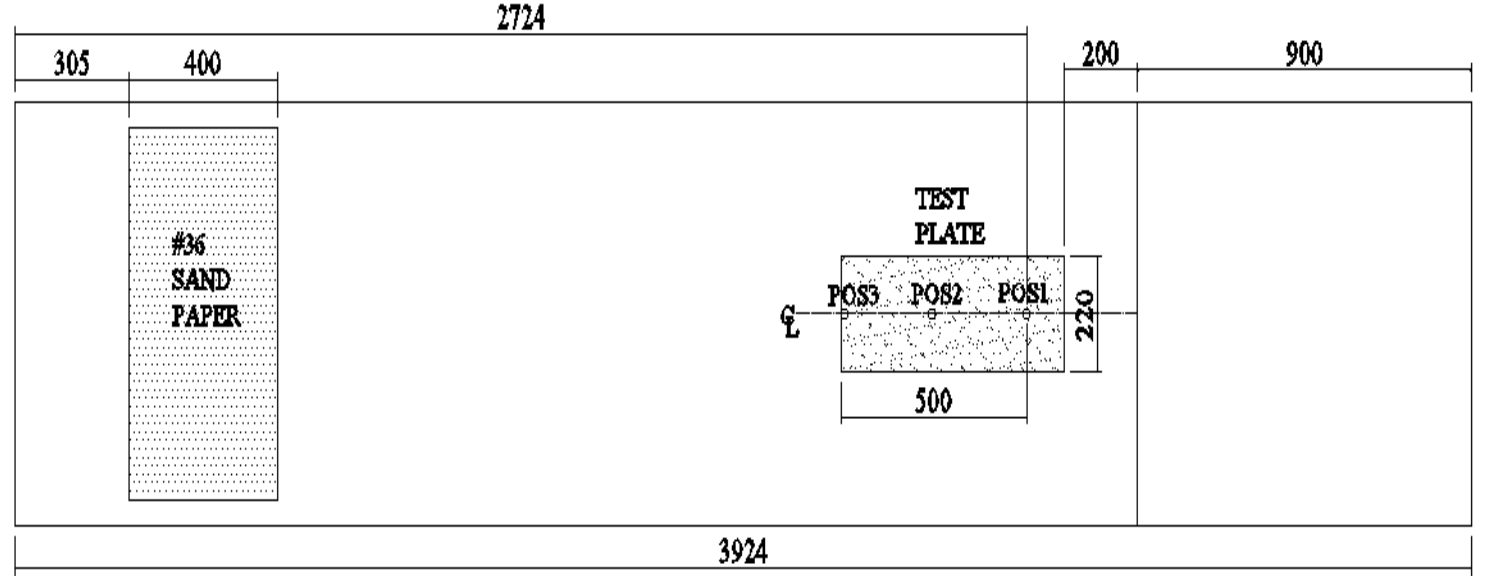

Fig. 1 Details of the test plate

Table 1 Tested surfaces as a summary

\begin{tabular}{ll}
\hline Abbreviation & Surface \\
\hline FR & Foul(ing) Release (FR) coating spray-applied \\
HC & Hard coating spray-applied \\
SPC & Self-Polishing Co-polymer (SPC) coating spray-applied \\
FRR & Foul(ing) Release (FR) coating applied by rollering \\
SAND40 & 40 grade sand paper \\
ACRYLIC & Acrylic as smooth reference \\
\hline
\end{tabular}

2.2 The Surface Roughness Characteristics of the Tested Surfaces

Roughness measurements were run with a laser profilometry for each test plate at intervals of $25 \mu \mathrm{m}$ on areas of $60 \mathrm{~mm}$ by $90 \mathrm{~mm}$. Obtained roughness profiles were analysed at different cut-off lengths using a Matlab program. Table 2 presents the results obtained for a $50 \mathrm{~mm}$ cutoff length.

Table 2 Surface roughness parameters, $50 \mathrm{~mm}$ cut-off length

\begin{tabular}{ccccccc}
\hline Surface & $\begin{array}{c}\mathrm{Rt} \\
(\mu \mathrm{m})\end{array}$ & $\begin{array}{c}\mathrm{Ra} \\
(\mu \mathrm{m})\end{array}$ & $\begin{array}{c}\mathrm{Rq} \\
(\mu \mathrm{m})\end{array}$ & $\begin{array}{c}\mathrm{Sk} \\
\mathrm{Ku}\end{array}$ & $\begin{array}{c}\mathrm{Sm} \\
(\mu \mathrm{m})\end{array}$ \\
\hline FR & 46.7 & 8.0 & 9.6 & -0.1 & 2.4 & 1167.7 \\
HC & 56.4 & 10.4 & 12.9 & 0.3 & 2.7 & 1570.2 \\
SPC & 45.3 & 7.6 & 9.4 & -0.2 & 2.9 & 816.5 \\
FRR & 159.7 & 23.2 & 31.2 & 1.0 & 4.5 & 2367.6 \\
SAND40 & 804.3 & 99.1 & 125.8 & 0.6 & 3.5 & 1248.6 \\
\hline
\end{tabular}


Rt, from the roughness parameters presented in Table 2, shows the maximum difference between the roughness hump and trough point in a cut-off length. Ra is the average roughness height, and $\mathrm{Rq}$ is the root-mean-square (RMS) of the roughness profile. Sk and Ku express the skewness and kurtosis of roughness height probability density functions, respectively. On the other hand, $\mathrm{Sm}$ indicates the distance between two peaks in the roughness profile. The values given in the table are the average values obtained for a total of 102 the roughness profiles. According to the results, the roughness parameters related to the mean height of the FR and SPC test plates are of the same order. On the other hand, application by rolling greatly increased the roughness heights of the surface. It has been found that the HC test plate has the highest roughness between the surfaces subjected to application by spraying. On the other hand, the sand paper surface, SAND40, has rather higher roughness amplitudes than the others. FRR and SAND40 test plates were found to have higher skewness than normal distribution; which indicates that the roughness distributions of the respective surfaces are sharper peaked and longer tailed. If so, it can be assumed that the roughness heights are usually concentrated at certain values, and very high and very small values are relatively rare. It is also possible to say that spray-coated surfaces, which show smaller $\mathrm{Ku}$ values than 3, exhibit flatter peaked and thick tailed distributions.

\subsection{Data Analysis Methods and Uncertainty Estimates}

Analysis of the velocity-time data collected in the boundary layer were carried out with the a Matlab program and a MS Excel program. The raw data were first filtered in the Matlab for noise elimination using the Chauvenet criterion [31]. Then the velocity components in the flow direction and the wall-normal direction are calculated by coordinate transformation. Subsequently, the moments of the velocities were taken with the transit time averaging technique. In order to determine the friction velocity, velocity profile fitting method and total stress method were applied as in [32] and [33], respectively. There is a maximum of $2.3 \%$ difference between the results of the two methods, which is consistent with the literature [34]. In this article, only the total stress method results will be presented.

Two methods were used for the uncertainty analysis. The method of [35] was used to account for the statistical uncertainty associated with the random sampling and limited sample population. On the other hand, repetitive tests were performed for the calculation of uncertainty according to [31] for the calculation of uncertainty due to possible inconsistencies in the experimental setup. 95\% confidence bounds were used in both uncertainty analysis procedures.

The uncertainty levels in the streamwise and transverse velocities are $1.18 \%$ and $7.82 \%$ between $y / \delta=0.05$ and $y / \delta=0.1$ in average. The mean uncertainty in $\mathrm{U}$ and $\mathrm{V}$ for $y / \delta>$ 0.1 can be given as $1.12 \%$ and $2.48 \%$, respectively. The average uncertainty percentages for $\overline{u u}, \overline{v v}$ and $\overline{u v}$ are $1.30 \%, 1.62 \%$ and $2.93 \%$ respectively between $0.02<y / \delta<0.15$. The average uncertainty in $\overline{u u}, \overline{v v}$ and $\overline{u v}$ are $2.01 \%, 1.97 \%$ and $3.72 \%$ respectively for $0.15<$ $y / \delta$. The average uncertainty for the friction velocity and local skin friction coefficient values which were calculated with the total stress method were determined as $1.37 \%$ and $3.29 \%$ whilst the maximum uncertainty in the calculated roughness functions was $7.58 \%$ for the tested surfaces. 


\section{Experimental Results}

For all the tested surfaces, the average velocity profiles obtained at $6 \mathrm{~m} / \mathrm{s}$ testing freestream velocity are presented in Fig. 2 comparatively in non-dimensional form with the inner flow scales. The viscous velocity profile and the logarithmic rule for smooth walls [36] are also present in the figure for comparison. The total stress method was used to determine the frictional velocities, which were then used for obtaining non-dimensional velocity profiles. It is seen that the average velocity profiles formed over the ACRYLIC plate, which is the smooth reference surface, are highly compatible with the logarithmic rule. When examined by the given scaling, the velocity profiles are expected to move downward and slightly to the right with the effect of roughness. Although not very obvious, it can be said that the FR and HC surfaces show a slight downward shift. On the other hand, the FRR surface and especially the fully rough reference surface SAND40 differ in severity from the smooth wall velocity profile. As expected, the velocity profiles of the surfaces show differences from the smooth wall logarithmic law depending upon the surface property, and a greater difference indicates a higher frictional resistance and roughness function expectation.

In Fig. 3, the velocity defect profiles showing the deviation of the mean velocity profiles from the free flow velocity are presented by Rotta scale, which is a mixture of inner and outer scales, for all test cases. The given graphic is an important indicator of the outer layer and wall similarity of [37]. As can be seen, all velocity defect profiles coincide exactly in the logarithmic and outer layers of the boundary layer. Accordingly, it can be said that the roughness effect remains specific to the inner layers of the boundary layer and that no significant difference is expected with the roughness effect on the wake strength parameter. This observation is consistent with, for example, [12]. In addition, while the friction velocity was calculated by the velocity profile fitting method, it was observed that the determined wake strength parameters change from 0.31 to 0.21 for all surfaces and test velocities. The different test surfaces were not necessarily effective on this change. These values are relatively low compared to the 0.52 value normally expected on the smooth wall [38]. This behavior can be attributed to the relatively high freestream turbulence intensity [33].

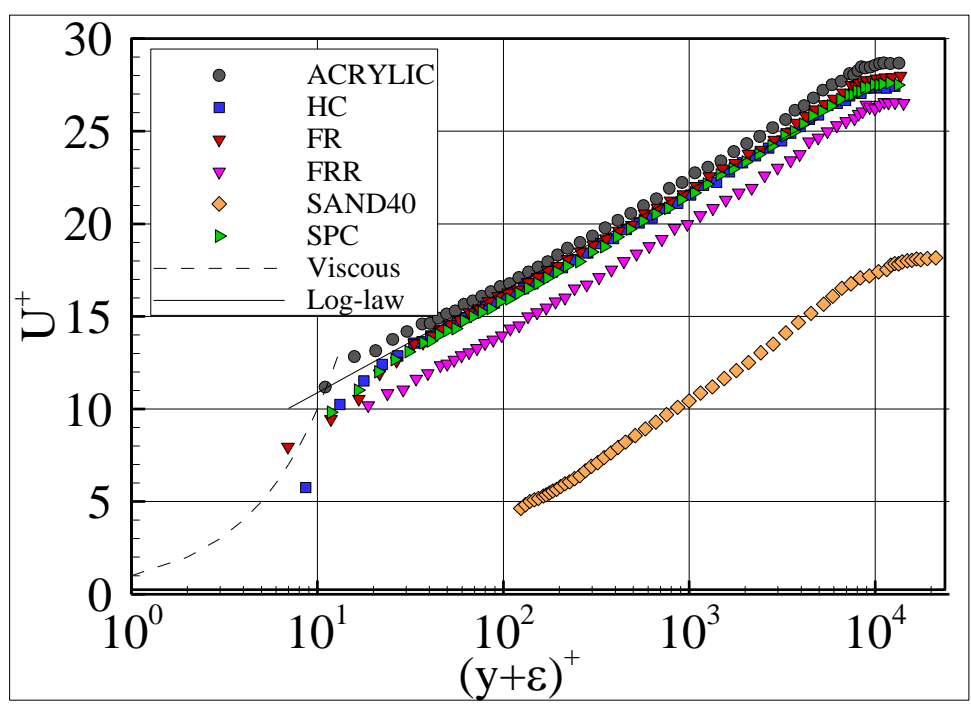

Fig. 2 Non-dimensional velocity profiles, inner scaling 


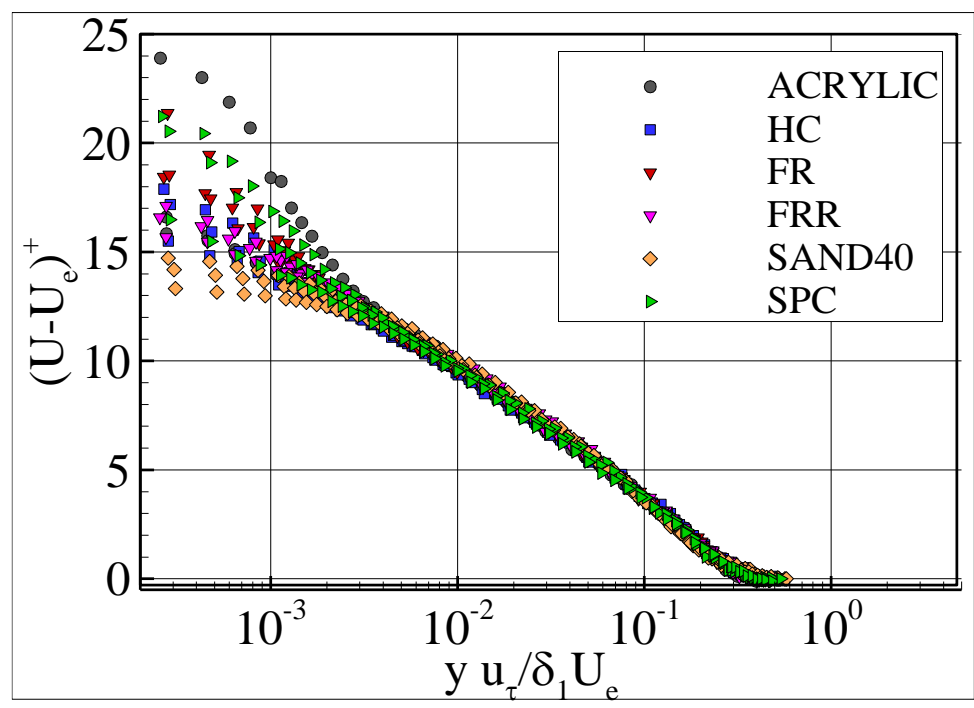

Fig. 3 Velocity defect profiles, Rotta scaling

The calculated local frictional resistance coefficients $(\mathrm{cf})$ and friction velocities $\left(\mathrm{u}_{\tau}\right)$ are presented in Table 3 together with the Reynolds number $\left(R e_{\delta 1}\right)$ depending on the displacement thickness for all test cases. As expected, as the test velocity increases, the friction velocity increases and the local frictional resistance coefficient decreases. Smooth reference ACRYLIC exhibits the lowest friction values, while the fully-rough reference SAND40 has a very high frictional resistance compared to all other surfaces. On the other hand, it was determined that the surface coated with the spray-applied foul release paint (FR) has a lower frictional resistance of 4.0 to $4.5 \%$ than that of the other coatings applied with spray. On the contrary, when the same coating was applied with rollering, 5.2\% higher average frictional resistance values were observed.

Table 4 also lists the roughness functions $\left(\Delta \mathrm{U}^{+}\right)$and roughness Reynolds numbers $\left(\mathrm{k}_{\mathrm{s}}^{+}\right)$ calculated with the total stress method, together with the Reynolds numbers $\left(R e_{\theta}\right)$ depending on the momentum thickness. The values of $k_{s}^{+}$presented were calculated by the formula given in Flack and Schultz (2010). According to this:

$$
k_{s}=4.43 R q(1+R s k)^{1.37}
$$

The [28] formula was found suitable for use in this work, as it is based on surface roughness data obtained with $25 \mu \mathrm{m}$ short and $50 \mathrm{~mm}$ long cut-off lengths. As shown in Table 3, the roughness functions are in parallel with the frictional resistance. Very low roughness functions have been achieved for all painted surfaces. On the other hand, the SAND40 surface, which is in a fully-rough regime, exhibited very high roughness functions compared to other tested surfaces. All surfaces showed a trend with increasing roughness function values as the Reynolds number of increases. 
Table 3 Friction velocities and local frictional resistance coefficients

\begin{tabular}{|c|c|c|c|}
\hline Surface & $R e_{\delta 1}$ & $u_{\tau}$ & $c_{f} \times 10^{3}$ \\
\hline ACRYLIC_POS1_2 & 10049 & 0.0771 & 2.86 \\
\hline ACRYLIC_POS1_4 & 17600 & 0.1462 & 2.60 \\
\hline ACRYLIC_POS1_6 & 25950 & 0.2120 & 2.43 \\
\hline HC_POS1_2 & 8893 & 0.0782 & 2.99 \\
\hline HC_POS1_4 & 16407 & 0.1510 & 2.78 \\
\hline HC_POS1_6 & 23565 & 0.2220 & 2.66 \\
\hline FR_POS1_2 & 9701 & 0.0780 & 2.93 \\
\hline FR_POS1_4 & 16569 & 0.1485 & 2.69 \\
\hline FR_POS1_6 & 25620 & 0.2180 & 2.55 \\
\hline FRR_POS1_2 & 10851 & 0.0805 & 3.14 \\
\hline FRR_POS1_4 & 18739 & 0.1574 & 2.99 \\
\hline FRR_POS1_6 & 27639 & 0.2289 & 2.85 \\
\hline SPC_POS1_2 & 9542 & 0.0778 & 2.93 \\
\hline SPC_POS1_4 & 17269 & 0.1520 & 2.78 \\
\hline SPC_POS1_6 & 24589 & 0.2210 & 2.65 \\
\hline SAND40_POS1_2 & 13499 & 0.1124 & 5.97 \\
\hline SAND40_POS1_4 & 24775 & 0.2258 & 6.17 \\
\hline SAND40_POS1_6 & 36541 & 0.3352 & 6.07 \\
\hline
\end{tabular}

The Reynolds number dependence of the roughness functions on the surfaces and the compliance with the Colebrook-White law can be examined in Fig. 4. The graph also includes correlations given by [39] and [40] for comparison. In addition, data from the transition regime of [34] have been added to the graph. Mentioned comparative data from [34] were obtained at different free flow velocities for a single regular rough surface and exhibit positive roughness function values starting from $k_{s}^{+}=2.5$ and are more closely related to the correlation given by Ligrani and Moffat (1986). The [34] surface roughness data was also obtained with $25 \mu \mathrm{m}$ short and $50 \mathrm{~mm}$ long cut-off lengths. One should note that this data is added to the graph as an example of regularly rough surface which does not fit to Colebrook-White law and should not be compared with the roughness function behavior of fouling control coated surfaces of this study. 
Table 4 Roughness functions and roughness Reynolds numbers

\begin{tabular}{|c|c|c|c|}
\hline Surface & $R e_{\theta}$ & $\Delta U^{+}$ & $k_{s}^{+}$ \\
\hline ACRYLIC_POS1_2 & 7826 & - & - \\
\hline ACRYLIC_POS1_4 & 14173 & - & - \\
\hline ACRYLIC_POS1_6 & 21134 & - & - \\
\hline HC_POS1_2 & 6995 & 0.30 & 5.4 \\
\hline HC_POS1_4 & 13204 & 0.75 & 10.6 \\
\hline HC_POS1_6 & 19125 & 1.01 & 15.6 \\
\hline FR_POS1_2 & 7652 & 0.22 & 2.4 \\
\hline FR_POS1_4 & 13246 & 0.37 & 4.2 \\
\hline FR_POS1_6 & 20776 & 0.65 & 6.7 \\
\hline FRR_POS1_2 & 8442 & 1.40 & 27.2 \\
\hline FRR_POS1_4 & 14790 & 2.04 & 50.6 \\
\hline FRR_POS1_6 & 22068 & 2.30 & 74.8 \\
\hline SPC_POS1_2 & 7445 & 0.19 & 2.1 \\
\hline SPC_POS1_4 & 13732 & 0.90 & 4.1 \\
\hline SPC_POS1_6 & 19964 & 1.04 & 5.9 \\
\hline SAND40_POS1_2 & 9454 & 8.83 & 104.3 \\
\hline SAND40_POS1_4 & 17360 & 10.55 & 205.3 \\
\hline SAND40_POS1_6 & 25924 & 11.31 & 308.4 \\
\hline
\end{tabular}

The roughness functions of the fully-rough SAND40 from this study fit perfectly with the roughly asymptotic line of the Colebrook-White law. The roughness functions of SPC and FR surfaces are usually distributed between the correlations of [39] and [40] for $k_{s}^{+}<10$. On the other hand, the increasing roughness Reynolds numbers of HC and FRR surfaces do not show the expected increase in their roughness functions and reflects much lower values than in all other correlations given in the literature. Besides, it is clear that the surfaces coated with different type marine coatings do not comply with the Colebrook-White law, and exhibit fairly low roughness functions compared to Colebrook-White law for examined roughness Reynolds number range.

Fig. 4 also includes data from [41], who also performed experiments for the rollering application of a different type FR marine coating, for comparison. While the first three points of [41]'s data are close to the correlation of [39], the following two points form a completely separate trend similar to the data in the present study. In fact, the final point coincides with the first value of the FRR in this study. The reason for the dispersion in [41] is thought to be related to the uncertainty that can be found naturally in experiments, as well as the fact that data are collected at different locations in the flow direction. 
On the other hand, it is clearly seen that the data obtained as a result of this study complement each other for different types of fouling control coatings, creating a completely distinct tendency in the range of $10 \leq k_{s}^{+}<100$. According to this observation, two different types of correlations can be proposed, namely the power function type and the Colebrook type, respectively:

$$
\Delta U^{+}=0.1302\left(k_{s}^{+}\right)^{0.7008}
$$

and

$$
\Delta U^{+}=2.2 \ln \left(1+0.03 k_{s}^{+}\right)
$$

Equations (2) and (3) are also printed in Figure 4. As can be seen, the two correlations show very good agreement with the data obtained for marine fouling control coatings tested in this study except for the two higher roughness Reynolds number data gathered for the SPC surface. On the other hand, the available data are limited from the top with $k_{s}^{+} \approx 100$, and the behavior of these surfaces in the higher Reynolds number range is still unclear.

It is seen that; surfaces coated with new generation marine fouling control coatings do not comply with the most important correlations in the literature. Moreover, at around $k_{s}^{+} \approx 70$, in which a transition to fully rough flow regime is expected [42], roughness function values much lower than expected are also observed. Accordingly, it is clear that for such surfaces, it is necessary to extend the number of data in this study to include particularly higher Reynolds numbers, in order to determine new correlations and to confirm the given correlations in this work.

On the other hand, it can be said that the use of a complex roughness length scale which accounts for several characteristic surface roughness parameters seems to be more suitable in the derivation of a correlation between frictional drag and surface roughness for irregularly rough surfaces as in this study. It should be born in mind that the measurement procedure and filter selection in the analysis plays an important role in the calculation of surface roughness parameters and a standard procedure is needed in order to achieve a consistent correlation between surface roughness and roughness function. 


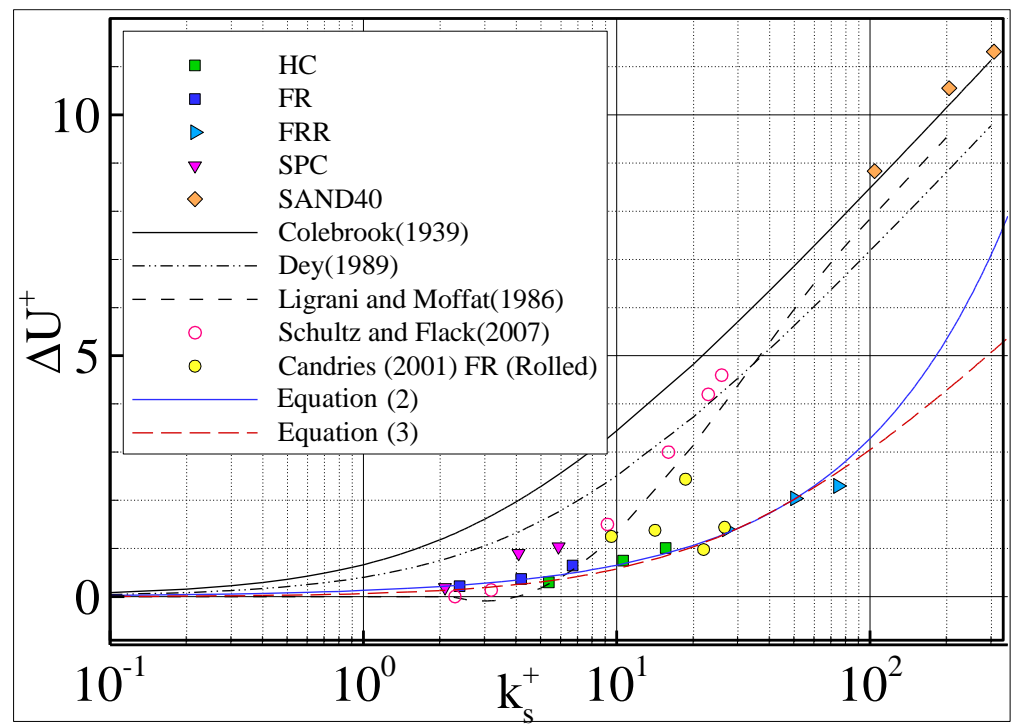

Fig. 4 The change of roughness functions with the roughness Reynolds number

\section{Conclusions}

In this study, flat plate turbulent boundary layer tests were performed with an LDV system on surfaces coated with new generation marine fouling control coatings in different types and the effect of roughness on the average flow parameters and on the frictional resistance was investigated in the transitionally rough flow regime. Key findings from the study can be summarized as follows:

Outer layer similarity was observed for both the surfaces covered with marine fouling control coatings and the fully rough reference surface by the comparison of velocity defect profiles in Rotta scale, which is an important indicator of the outer layer and wall similarity.

For the spray-applied new generation Foul-Release type marine antifouling coated surface, a frictional resistance reduction of up to $4.5 \%$ was captured compared to other marine fouling control coatings which were also applied with the same technique.

None of the tested marine fouling control coatings showed compliance with Colebrook-White law with their roughness functions creating a completely distinct trend in the range of $10 \leq$ $k_{s}^{+}<100$ and at around $k_{s}^{+} \approx 70$, in which a transition to fully rough flow regime is expected, much lower than expected roughness function values were observed.

Accordingly, two new correlations between roughness and frictional resistance have been proposed to represent the behavior of these surfaces by using a complex roughness length scale. However, for confirming the validity of these correlations at the higher Reynolds number range and for other types of irregular surfaces, it would be appropriate to extend this study. 


\section{Acknowledgements}

I would like to thank Prof. Dr. Mehmet Atlar, who supported this study by several means such as providing access to the experiments supported by International Paint Ltd. AkzoNobel and offering the capabilities of the Emerson Cavitation Tunnel. I would also like to express my gratitude to the ITU Rectorate and the Dean of ITU Naval Architecture and Ocean Engineering Faculty for their support for my research visit to the University of Newcastle.

\section{References}

[1] Schultz, M.P. (2007). Effects of Coating Roughness and Biofouling on Ship Resistance and Powering. Biofouling, 23(5), 331-341. https://doi.org/10.1080/08927010701461974

[2] Schultz, M.P., Bendick, J.A., Holm, E.R., and Hertel, W.M. (2011). Economic Impact of Biofouling on a Naval Surface Ship. Biofouling, 27, 87-98. https://doi.org/10.1080/08927014.2010.542809

[3] Demirel, Y.K., Uzun, D., Zhang, Y., Fang, H-C, Day, A.H., Turan, O. (2017). Effect of Barnacle Fouling on Ship Resistance and Powering, Biofouling, 33:10, 819-834. https://doi.org/10.1080/08927014.2017.1373279

[4] Candries, M., and Atlar, M. (2005). Experimental Investigation of The Turbulent Boundary Layer of Surfaces Coated with Marine Fouling control coatings. Journal of Fluids Engineering Transactions of ASME, 127, 219232. https://doi.org/10.1115/1.1891148

[5] Ünal, U.O., Ünal, B., Atlar, M. (2012). Turbulent Boundary Layer Measurements over Flat Surfaces Coated by Nanostructured Marine Fouling control coatings. Experiments in Fluids, 52(6), 1431-1448. https://doi.org/10.1007/s00348-012-1262-z

[6] Perry, A.E., Schofield, W.H., and Joubert, P.N. (1969). Rough-Wall Turbulent Boundary Layer. Journal of Fluid Mechanics, 37, 383-413. https://doi.org/10.1017/S0022112069000619

[7] Krogstad, P.A., and Antonia, R.A. (1999). Surface Roughness Effects in Turbulent Boundary Layers. Experiments in Fluids, 27, 450-460. https://doi.org/10.1007/s003480050370

[8] Djenidi, L., Elavarasan, E., and Antonia, R.A. (1999). Turbulent Boundary Layer over Transverse Square Cavities. Journal of Fluid Mechanics, 395, 271-294. https://doi.org/10.1017/S0022112099005911

[9] Akinlade, O.G., Bergstrom, D.J., Tachie, M.F., and Castillo, L. (2004). Outer Flow Scaling of Smooth and Rough Wall Turbulent Boundary Layers. Experiments in Fluids, 37, 604-612. https://doi.org/10.1007/s00348$\underline{004-0856-5}$

[10] Schultz, M.P., and Flack, K.A. (2005). Outer Layer Similarity in Fully Rough Turbulent Boundary Layers. Experiments in Fluids, 38, 328-340. https://doi.org/10.1007/s00348-004-0903-2

[11] Pailhas, G., Touvet, Y., and Aupoix, B. (2008). Effects of Reynolds Number and Adverse Pressure Gradient on a Turbulent Boundary Layer Developing on a Rough Surface. Journal of Turbulence, 9(43), 1-24. https://doi.org/10.1080/14685240802562020

[12] Schultz, M.P., and Flack, K.A. (2009). Turbulent Boundary Layers on a Systematically Varied Rough Wall. Physics of Fluids, 21, 015104. https://doi.org/10.1063/1.3059630

[13] Volino, R.J., Schultz, M.P., and Flack, K.A. (2009). Turbulence Structure in a Boundary Layer with TwoDimensional Roughness. Journal of Fluid Mechanics, 635, 75-101. https://doi.org/10.1017/S0022112009007617

[14] Brzek, B., Chao, B., Turan, Ö., and Castillo, L. (2010). Characterizing Developing Adverse Pressure Gradient Flows Subject to Surface Roughness. Experiments in Fluids, 48, 663-677. https://doi.org/10.1007/s00348-009$\underline{0759-6}$ 
[15] Schultz, M.P. (1998). The Effect of Biofilms on Turbulent Boundary Layers. DPhil Thesis, Florida Institute of Technology, Melbourne, Florida.

[16] Schultz, M.P. (2000). Turbulent Boundary Layers on Surfaces Coated with Filamentous Algae. Journal of Fluids Engineering Transactions of ASME, 122, 357-362. https://doi.org/10.1115/1.483265

[17] Schultz, M.P. (2004). Frictional Resistance of Antifouling Coating Systems. ASME Journal of Fluids Engineering, 126, 1039-1047. https://doi.org/10.1115/1.1845552

[18] Wu, Y., and Christensen, K.T. (2010). Spatial Structure of a Turbulent Boundary Layer with Irregular Surface Roughness. Journal of Fluid Mechanics, 655, 380-418. https://doi.org/10.1017/S0022112010000960

[19] Mejia-Alverez, R., and Christensen, K.T. (2010). Low-Order Representations of Irregular Surface Roughness and Their Impact on a Turbulent Boundary Layer. Physics of Fluids, 22, 015106. https://doi.org/10.1063/1.3291076

[20] Bons, J.P. (2010). A Review of Surface Roughness Effects in Gas Turbines. Journal of Turbomachinery Transactions of ASME, 132, 021004. https://doi.org/10.1115/1.3066315

[21] Atlar, M., Ünal, B., Ünal, U.O., Politis, G., Martinelli, E., Galli, G., Davies, C., Williams, D. (2013). An Experimental Investigation of the Frictional Drag Characteristics of Nanostructured and Fluorinated FoulingRelease Coatings Using an Axisymmetric Body. Biofouling, $29 \quad$ (1), 39-52. https://doi.org/10.1080/08927014.2012.745856

[22] Ünal, U.O. (2015). Correlation of Frictional Drag and Roughness Length Scale for Transitionally and Fully Rough Turbulent Boundary Layers. Ocean Engineering, 107, 283-298. https://doi.org/10.1016/j.oceaneng.2015.07.048

[23] Demirel, Y.K., Khorasanchi, M., Turan, O., Incecik, A. (2014). A CFD Model for the Frictional Resistance Prediction of Antifouling Coatings, Ocean Engineering, 89, 21-31. https://doi.org/10.1016/j.oceaneng.2014.07.017

[24] Demirel, Y.K., Turan, O., Incecik, A. (2017b). Predicting the Effect of Biofouling on Ship Resistance Using CFD, Applied Ocean Research, 62, 100-118. https://doi.org/10.1016/j.apor.2016.12.003

[25] Song, S., Demirel, Y.K., Atlar, M. (2019). An Investigation into the Effect of Biofouling on the Ship Hydrodynamic Characteristics Using CFD, Ocean Engineering, 175, 122-137. https://doi.org/10.1016/j.oceaneng.2019.01.056

[26] Farkas, A., Degiuli, N., Martic, I. (2018). Towards the Prediction of the Effect of Biofilm on the Ship Resistance Using CFD, Ocean Engineering, 167, 169-186. https://doi.org/10.1016/j.oceaneng.2018.08.055

[27] Schultz, M.P., Walker, J.M., Steppe, C.N., Flack, K.A. (2015). Impact of Diatomaceus Biofilms on the Frictional Drag of Fouling-Release Coatings, Biofouling, $31 \quad$ (9-10), 759-773. https://doi.org/10.1080/08927014.2015.1108407

[28] Flack, K.A., and Schultz, M.P. (2010). Review of Hydraulic Roughness Scales in the Fully Rough Regime. Journal of Fluids Engineering, 132, 041203. https://doi.org/10.1115/1.4001492

[29] Colebrook, C.F. (1939). Turbulent Flows in Pipes with Particular Reference to the Transition Region between the Smooth and Rough Pipe Flows. Journal of the Institution of Civil Engineers, 11,133-155. https://doi.org/10.1680/ijoti.1939.13150

[30] Candries, M., Atlar, M., Mesbahi, E., and Pazouki, K. (2003) The Measurement of the Drag Characteristics of Tin-Free Self-Polishing Co-Polymers and Fouling Release Coatings Using a Rotor Apparatus. Biofouling, 19, 27-36. https://doi.org/10.1080/0892701021000026138

[31] Coleman, H.W., and Steele, W.G. (2009). Experimentation and Uncertainty Analysis for Engineers. NewYork: John Wiley\&Sons. https://doi.org/10.1002/9780470485682 
[32] Krogstad, P.A., Antonia, R.A., Browne, L.W.B. (1992). Comparison between Rough and Smooth Wall Turbulent Boundary Layers. Journal of Fluid Mechanics, 245, 599-617. https://doi.org/10.1017/S0022112092000594

[33] Brzek, B., Torres-Nieves, S., Lebron, J, Cal, R., Meneveau, C., and Castillo, L. (2009). Effects of Freestream Turbulence on Rough Surface Turbulent Boundary Layers. Journal of Fluid Mechanics, 635, 207-243. https://doi.org/10.1017/S0022112009007447

[34] Schultz, M.P., and Flack, K.A. (2007) The Rough-Wall Turbulent Boundary Layer from the Hydraulically Smooth to the Fully Rough Regime. Journal of Fluid Mechanics, 580, 381-405. https://doi.org/10.1017/S0022112007005502

[35] Benedict, L.H., and Gould, R.D. (1996). Towards Better Uncertainty Estimates for Turbulence Statistics. Experiments in Fluids, 22, 129-136. https://doi.org/10.1007/s003480050030

[36] Clauser, F.H. (1956). The Turbulent Boundary Layer. Advances in Applied Mechanics, 4, 1-51. https://doi.org/10.1016/S0065-2156(08)70370-3

[37] Townsend, A.A. (1976). The Structure of Turbulent Shear Flow, Cambridge University Press, Cambridge.

[38] Bandyopadhyay, P.R. (1987). Rough-Wall turbulent Boundary Layers in the Transition Regime. Journal of Fluid Mechanics, 180, 231-266. https://doi.org/10.1017/S0022112087001794

[39] Ligrani, P.M., and Moffat, R.J. (1986). Structure of Transitionally Rough and Fully Rough Turbulent Boundary Layers. Journal of Fluid Mechanics, 162, 69-98. https://doi.org/10.1017/S0022112086001933

[40] Dey, S.K. (1989). Parametric Representation of Hull Painted Surfaces and the Correlation with Fluid Drag. PhD Thesis, Department of Marine Technology, University of Newcastle upon Tyne, Newcastle upon Tyne.

[41] Candries, M. (2001). Drag, Boundary-Layer and Roughness Characteristics of Marine Surfaces Coated with Fouling control coatings. PhD Thesis, Department of Marine Technology, University of Newcastle upon Tyne, Newcastle upon Tyne.

[42] Schlichting, H. (1979). Boundary Layer Theory. McGraw-Hill, New York.

Submitted: $\quad$ 06/05/2018 Burcu ERBAŞ, erbasburc@itu.edu.tr

Accepted: $\quad 19 / 12 / 2019$

Istanbul Technical University Naval Architecture and Ocean Engineering Faculty, 34469, Ayazaga, Istanbul, Turkey 